RU Сослагательное наклонение настоящего времени (Present Subjunctive) в английском языке. Холистическое осмысление

\author{
Жулина Е. Б.
}

\begin{abstract}
Аннотация. Цель исследования - определить, как сослагательное наклонение настоящего времени (Present Subjunctive) в английском языке отражает опыт наблюдателя и понятийное знание говорящего. Научная новизна исследования состоит в трактовке данной языковой формы как выражающей особенности восприятия человеком мира в процессе его встраивания в среду в момент речи. При этом контекст ситуации и особенности восприятия рассматриваются как ключевые в интерпретации языка. В результате впервые показано, что эта форма передает противопоставление непосредственного опыта наблюдателя и понятийного знания говорящего, приводящее к отрешенности сознания в момент речи и возникновению эффекта «сослагательности» события.
\end{abstract}

\title{
EN Present Subjunctive in the English Language. Holistic Approach
}

\section{Zhulina E. B.}

\begin{abstract}
The paper aims to study how the Present Subjunctive in the English language reflects the viewer's experience and the speaker's conceptual knowledge. The scientific originality of the research lies in the interpretation of this language form as expressing the characteristics of the man's perception of the world in the process of their adaptation to the surroundings at the moment of speech. At the same time, the situational context and the perception characteristics are considered as the key ones in the language interpretation. As a result, it has been shown that this form delivers the contrast between the viewer's direct experience and the speaker's conceptual knowledge which leads to the detachment of mind at the moment of speech and the effect of a "subjunctive" event.
\end{abstract}

\section{Введение}

Актуальность темы исследования определяется общей сосредоточенностью современной гуманитарной науки на фигуре человека как субъекта познания и явно созревшей необходимостью интерпретировать язык как антропоцентричную, всеобъемлющую символьную систему. В рамках холистического подхода структуры, присутствующие в сознании человека и передаваемые словами, в значительной степени детерминируются опытом его тела (Kravchenko, 2016; Varela, Thompson, Rosch, 2017). Обусловленность структур сознания телесным опытом приводит к трактовке языка как формы когнитивного поведения, направленной на максимально эффективную адаптацию к среде в ситуации коммуникативного цейтнота, а не как самодовлеющей символьной системы, созданной только для общения, которую коммуникант присваивает в момент речи. Знание, отражаемое в языке, как следствие, считается чувственным опытом наблюдателя, непосредственным или опосредованным. Источником знания, выраженного в слове, всегда выступает наблюдатель, а не говорящий. Непосредственный чувственный опыт наблюдателя определяется как феноменологическое знание. Собственный предшествующий опыт наблюдателя служит промежуточным этапом между непосредственным опытом и знанием как понятием. Понятийное знание, наиболее абстрагированное от первоначального источника восприятия, описывается как структуральное.

Объективность знания, представленного в языке, потому только и возможна, что представляет собой чувственный опыт каждого отдельного человека. Принятие того, что знание суть телесный опыт человека, ведет к трактовке коммуникации как формы когнитивного поведения, направленного на максимально эффективное приспособление к среде в момент речи. В силу этого контекст ситуации, или речевой контекст, особенности восприятия человека как субъекта познания, а также соответствие языка чувственному опыту человека становятся ключевыми в исследовании языка.

Научная статья (original research article) | https://doi.org/10.30853/phil20220087

( 2022 Авторы. ООО Издательство «Грамота» (๔ 2022 The Authors. GRAMOTA Publishers). Открытый доступ предоставляется на условиях лицензии СС ВY 4.0 (open access article under the CС BY 4.0 license): https://creativecommons.org/licenses/by/4.0/ 
Человек считает реальностью только то, что дано ему в непосредственных ощущениях, то есть в настоящем. Как следствие, прошлое и будущее представляются умозаключениями, которые он строит, опираясь на свой опыт, хранимый в памяти. Другими словами, грамматическая категория наклонения суть знание человека о смене событий, которое он создает на основе того, как части пространства последовательно сменяются в поле его зрения.

Для достижения поставленной в работе цели необходимо решить четыре задачи. Во-первых, показать, что механизм дистанцирования, составляющий семантическую базу форм сослагательного наклонения настоящего времени (Present Subjunctive), обусловлен тем, что в акте коммуникации человек противопоставляет понятийное знание говорящего непосредственному опыту наблюдателя. Он сталкивает структуральное знание, выражаемое простым инфинитивом (Simple Infinitive) глагола be и простым инфинитивом (Simple Infinitive) остальных глаголов для всех лиц и чисел, сочетанием модальных глаголов (Modal Verbs) may/might, can/could, should с простым инфинитивом (Simple Infinitive) смыслового глагола, и опыт наблюдателя. Во-вторых, подтвердить, что сочетание модальных глаголов (Modal Verbs) may/might, can/could, should с простым инфинитивом (Simple Infinitive) передает только структуральное знание говорящего. В-третьих, доказать, что простой инфинитив (Simple Infinitive) глагола be отражает не только структуральное знание говорящего, но и непосредственный опыт наблюдателя, который преобладает. В-четвертых, продемонстрировать, что сочетание предлога whatever и подобных ему и формы сослагательного наклонения настоящего времени (Present Subjunctive) глагола $\boldsymbol{b} \boldsymbol{e}$ в придаточных предложениях уступки передает только структуральное знание говорящего.

При интерпретации форм сослагательного наклонения настоящего времени (Present Subjunctive) в пределах холистического подхода в статье применялись следующие методы исследования: когнитивный анализ, разработанный M. Льюисом (Lewis, 1991, c. 34), и контекстный анализ. Первый опирается на принятие двух особенностей. С одной стороны, того, что видовременные формы глагола необходимо анализировать как сумму отдельных, самодостаточных частей, сложение которых приводит к правильному выражению ею значения. С другой стороны, того, что выбор человеком глагольной формы зависит от особенностей его восприятия мира. Последний призван, помимо прочего, показать значимость речевого контекста, или контекста ситуации, при анализе языковых единиц. В качестве материала для изучения выступили высказывания, взятые из British National Corpus (2022).

Теоретической базой исследования послужил самый широкий спектр междисциплинарных работ, лежащих в пределах социокультурной и естественнонаучной парадигмы: начиная с собственно лингвистических (Моррис, 1983), семиотических (Chomsky, Berwick, 2017) и работ по биологии языка (Kravchenko, 2016; Varela, Thompson, Rosch, 2017) и заканчивая исследованиями в сфере философии (Мамардашвили, 1996), психологии (Леонтьев, 1977), философии сознания (Pinker, 2021; Verny, 2021; Blomqvist, 2021), нейронауки (Feldman Barrett, 2020).

Практическая значимость исследования состоит в том, что осмысление форм сослагательного наклонения в английском языке с позиции характера отражаемого знания может применяться в вузах гуманитарного направления при изучении спецкурсов и спецсеминаров по когнитивной грамматике, когнитивной семантике, прикладной лингвистике, сравнительному языкознанию, психологии сознания, литературной и театральной критике. Полученные данные могут найти применение в процессе учебно-методической деятельности при создании учебников, учебных пособий по преподаванию английского языка на уровне B2, C1.

\section{Основная часть}

Классическое языкознание и когнитивная лингвистика «первого поколения» при интерпретации сослагательного наклонения настоящего времени (Present Subjunctive) в английском языке позицию наблюдателя не выделяют (Есперсен, 1958, с. 313; Sweet, 1958, с. 32). Однако при рассмотрении роли наблюдателя в языке привлекает внимание следующее.

Во-первых, разделение на типы наклонений происходит не по критерию временной отнесенности, а по степени реальности действия. Подобное разделение может провести только человек в процессе непосредственного наблюдения внешнего и внутреннего мира.

Во-вторых, признание ошибочным стремления приравнять нереальность, гипотетичность действия только к формам простого прошедшего времени (Past Simple). Иначе говоря, оценить характер действия как относящийся к реальности можно лишь на основе непосредственного наблюдения.

В-третьих, истинными формами сослагательного наклонения настоящего времени (Present Subjunctive) в английском языке считаются простые инфинитивы (Simple Infinitive) смысловых глаголов для всех лиц и чисел и сочетание модальных глаголов (Modal Verbs) may/might, can/could и should с простым инфинитивом (Simple Infinitive) смыслового глагола. Другими словами, употребление простого инфинитива (Simple Infinitive) смыслового глагола для всех лиц и чисел при выражении грамматической категории сослагательности подразумевает противопоставление как минимум двух типов знания. Очевидно, что этими типами знания выступают непосредственный или опосредованный опыт наблюдателя и понятийное знание говорящего. Разделить знание на данные группы может только человек как субъект познания, выделяя их в сравнении с собственным опытом.

B-четвертых, форма простого настоящего времени (Present Simple) только «заменяет формы будущего и прошедшего времени, оставаясь формой настоящего времени» (Смирницкий, 1959, с. 346). Несомненно то, что замену формами настоящего времени может совершать только наблюдатель, выражая тем самым свой чувственный опыт.

B-пятых, разделение категории наклонения на сослагательное наклонение I (be) и сослагательное наклонение II (were) по критерию нереальности события, а не временной отнесенности (Смирницкий, 1959, с. 348). 
Такое разделение может опираться лишь на опыт наблюдателя, а не понятийное знание говорящего, поскольку определить соответствие события действительности можно только наблюдая его.

B-шестых, при употреблении «сослагательного наклонения I речь не идет ни о соответствии, ни о противопоставлении высказывания тому, что происходит в действительности» (Смирницкий, 1959, с. 350). Другими словами, интуитивно понимается, что значение «сослагательности» формы сослагательного наклонения настоящего времени (Present Subjunctive) создается человеком при противопоставлении двух типов знания феноменологического знания наблюдателя и понятийного знания говорящего.

В-седьмых, «при переходе “квази-номинативного” наклонения в сослагательное наклонение происходит переход из пространственной категории в категорию времени» (Hewson, 1997, с. 41, 42; Leech, 1987, с. 113, 129). Более чем очевидно то, что первичная категоризация реальности в терминах пространства возможна только при нахождении события в поле зрения наблюдателя. Иначе говоря, непосредственный опыт постижения пространства наблюдателем переходит в его опосредованный опыт или даже понятийное знание говорящего.

Как показывают наши исследования, отрешенность человека от момента речи строится по совершенно определенному когнитивному механизму. Рассмотрим примеры.

Выбирая высказывание: "His Grace will be sorely missed, alas!" "He will so - " agrees Anne gloomily, adding since it is clearly expected of her - "God rest his soul”. / Его Величество будут сильно оплакивать, увы! «Да, именно так», мрачно соглашается Анна и добавляет, поскольку этого от неё ожидают, - «упокоит Господь его душу» (здесь и далее перевод автора статьи. - Е. Ж.), наблюдатель видит герцогиню Йоркскую, жену Ричарда III, стоящую вместе с матерью и придворными у гроба своего свекра, короля Англии, и посылающую ему последнее прощание. Как следствие, он использует простое причастие настоящего времени adding, которое, как -ing форма, выражает восприятие действия как процесса, разворачивающегося во времени в поле зрения наблюдателя. Помимо этого, на присутствие наблюдателя в момент речи указывает форма is, передающая, как простая форма глагола be, бытийность, которую можно лишь видеть. Притяжательное местоимение his передает непосредственный опыт наблюдателя, поскольку отношения принадлежности по оси «свой-чужой» человек всегда описывает относительно себя и своего личного пространства. При этом форма сослагательного наклонения настоящего времени (Present Subjunctive) rest, как базовая (в терминах М. Льюиса (Lewis, 1991, с. 17)), а не спряженная форма глагола, отражает структуральное знание говорящего. Иными словами, непосредственный опыт наблюдателя противопоставляется понятийному знанию говорящего. Как следствие, человек дистанцируется от момента речи и возникает эффект «сослагательности» действия.

В фразе: Anybody seen this? Can I suggest that we wind up the meeting and er? Yeah thanks for thanks for facilitating. / Кто-нибудь это видел? Предлагаю завершить совещание и э-э-э... Да, спасибо... спасибо за содействие - наблюдатель видит руководителя отдела продаж, который завершает рабочее совещание и благодарит всех присутствующих. В силу этого он выбирает личное местоимение $\boldsymbol{I}$, наиболее точно указывающее на существование и местоположение наблюдателя, поскольку определить себя как «я» можно только вследствие непосредственного наблюдения. Указательное местоимение this отражает присутствие наблюдателя, так как отдаленность объектов в пространстве человек всегда определяет относительно себя и своего места и, следовательно, должен это видеть. Личное местоимение wе передает непосредственный опыт наблюдателя, так как говорит о включенности объекта наблюдения в личное, психологическое пространство наблюдателя. Локативный предлог ир также выбирается только в случае непосредственного наблюдения, поскольку расположение объектов в пространстве по оси «верх-низ» описывается человеком относительно положения своего тела в пространстве. Определенный артикль the выражает ту степень определенности, какую можно только видеть. Перфектное причастие (Participle II) seen отражает опосредованный опыт наблюдателя, более не видимую часть ситуации, существующую в настоящем в виде результата. В то же время форма сослагательного наклонения настоящего времени (Present Subjunctive) wind выражает понятийное знание говорящего, максимально абстрагированное от первоначального источника восприятия. Как следствие, структуральное знание противопоставляется непосредственному чувственному опыту наблюдателя и создается эффект «сослагательности» высказывания.

Кроме того, то, что основой сослагательности высказывания служит отрешенность сознания человека от момента речи, косвенно подтверждается, во-первых, возможностью опущения глагола should и употребления только формы сослагательного наклонения настоящего времени (Present Subjunctive) для обозначения желательности события, рекомендации или предложения (Емельянова, Зеленщиков, Петрова, 2003, с. 213). Таким образом показывается также, что даже при дистанцировании от ситуации опыт наблюдателя (опосредованного типа) преобладает над структуральным знанием говорящего. Во-вторых, в британском варианте английского языка данная форма определяется принадлежностью исключительно официальному регистру (Емельянова, Зеленщиков, Петрова, 2003, с. 213). Иначе говоря, стилю повествования, прошедшему наибольшее количество этапов категоризации, и, следовательно, наиболее обезличенному стилю повествования.

Рассмотрим высказывание: Down there, there's a good boy... If he goes off and sulks for a while, well so be it... you'll have to sulk till you get used to it, there you are. / Где-то в глубине души он хороший мальчик. Если он вдруг начнет капризничать и делать все вам назло, да будет так... Пока не привыкните, вы так и будете обижаться. Вот так! Наблюдатель видит маму мальчика, рассказывающую новой няне о её обязанностях, характере будущего подопечного и нужном отношении к нему. В силу этого он выбирает локативное местоимение there, передающее положение в пространстве объекта только с точки зрения близости к наблюдателю. Употребление локативного наречия down возможно лишь с позиции наблюдателя, поскольку описание собственного внутреннего состояния как пространства доступно только на основе чувственного опыта. Спряженная форма are глагола be указывает на наблюдаемость ситуации, так как бытийность можно лишь видеть. Личное местоимение уои также 
передает непосредственный опыт наблюдателя, поскольку отражает систему «свой-чужой», восходящую к опыту, а не к понятию. Однако форма сослагательного наклонения настоящего времени (Present Subjunctive) глагола $\boldsymbol{b}$, как базовая форма глагола $\boldsymbol{b}$, отражает структуральное знание говорящего, а не непосредственный опыт наблюдателя. Как следствие, понятийное знание сталкивается с опытом наблюдателя, и высказывание приобретает окраску сослагательности. При этом, поскольку в семантике глагола $\boldsymbol{b} \boldsymbol{e}$ отражена бытийность, то «сослагательность» ситуации сильно сдвигается в сторону опыта наблюдателя, непосредственного и опосредованного. Это делает высказывание скорее реальным, чем нереальным. Помимо этого, преобладание опыта наблюдателя над понятийным знанием говорящего в случае с глаголом be подтверждается использованием формы сослагательного наклонения настоящего времени (Present Subjunctive) в устойчивых выражениях, произнесение которых выступает как собственно действие. Действия «клятва», «проклятие», «благословление» и т.д. представляют собой не только максимальное совпадение события и его словесного описания, но и, будучи произнесенными, меняют реальность (Thomson, Martinet, 1997, с. 253). Другими словами, высказывания отражают, с одной стороны, знание, первоначальный источник которого вряд ли представляется возможным определить. С другой стороны, они передают непосредственный чувственный опыт наблюдателя, причем как внешний, так и внутренний, то есть позиция наблюдателя представлена наиболее полно.

В фразе: If you get married in a registry office, which I did, you don't say anything other than that you take this chap to be your husband, and be it as you wish. / Если вы решите пожениться в загсе, как сделала, например, я, тебе не нужно ничего говорить кроме как «я беру этого парня в мужья» и будь по-твоему - наблюдатель видит двух подруг, обсуждающих правила заключения официального брака. Он выбирает личное местоимение уои, описывающее другого человека только как находящегося в поле зрения наблюдателя. Указательное местоимение this выражает близость в пространстве по отношению к местоположению наблюдателя, указывая, таким образом, только на наблюдателя. Помимо этого, он употребляет частично измененное перформативное высказывание уоu take, выступающее само по себе действием и в случае пересказа демонстрирующее хотя и не непосредственный, но все же опыт наблюдателя, а не понятийное знание говорящего. В свою очередь, форма сослагательного наклонения настоящего времени (Present Subjunctive) be, будучи базовой формой глагола be, отражает бытие, «которое можно определить как таковое только при непосредственном зрительном восприятии» (Жулина, 2018, с. 105).

Например, высказывание: The World's Olympic athletes are forced to take second place here... snubbed so that TV might make another extravaganza of the closing ceremony... The gates are slammed in their faces so that preparations for the closing ceremony could take place. / Спортсменов мирового уровня заставляют, практически силой, занять лишь второе место на этих соревнованиях; унижают, только для того, чтобы телевидение могло превратить церемонию закрытия в очередную нелепую выходку... Ворота захлопываются у них прямо перед носом только для того, чтобы подготовить цееремонию закрытия. Наблюдатель видит, как крупных спортсменов вынуждают несправедливым судейством занять только второе место в чемпионате. Более того, их унижают только для того, чтобы позволить телевидению показать себя, и подготовка церемонии закрытия важнее спортивных результатов. Наблюдатель использует определенный артикль the, как передающий ту степень определенности, которую можно лишь наблюдать. Локативное наречие here всегда указывает на наблюдателя и его положение в пространстве. Причастие настоящего времени (Participle I) closing, как -ing форма, описывает видимую часть ситуации - последовательную смену событий в поле зрения наблюдателя. Форма are, как форма настоящего времени, также указывает на наблюдателя.

Вместе с тем аналитическая форма сослагательного наклонения настоящего времени (Present Subjunctive) might make и could take, представленная сочетанием модальных глаголов (Modal Verbs) might и could и простого инфинитива (Simple Infinitive) смыслового глагола make и take, выражает структуральное знание говорящего по двум причинам. С одной стороны, модальные глаголы (Modal Verbs) might и could, как глаголы, отображающие отношение человека к действию, а не собственно действие, передают понятийное знание говорящего. С другой стороны, формы простого инфинитива (Simple Infinitive) смыслового глагола make и take, как отглагольные имена, также отражают структуральное знание говорящего. Другими словами, столкновение непосредственного опыта наблюдателя и понятийного знания говорящего представляет событие как сослагательное.

Проанализируем пример: Whether they remain in Edinburgh or betake themselves to other lands and whatever be the walk of life in which they were bred I believe the students of this seminary will be found everywhere and at all times promoting civilization in the world. / Останутся ли они в Эдинбурге или отправятся в другие страны и независимо от их происхождения я верю, что студенты этой семинарии будут везде и всегда нести в мир идею цивилизации. Наблюдатель видит ректора семинарии в Эдинбурге, выступающего с напутственной речью перед выпускниками. Он употребляет личное местоимение $\boldsymbol{I}$, которое человек может применить лишь к себе. Помимо этого, в семантике глагола believe также содержится намек на наблюдателя. Таким образом, в целом вводная фраза I believe описывает непосредственный опыт наблюдателя. Определенный артикль the также отражает нахождение объекта в поле зрения наблюдателя. Указательное местоимение this передает опыт наблюдателя, так как указывает на непосредственное местоположение наблюдателя в момент речи. При этом сочетание предлога whatever и формы сослагательного наклонения настоящего времени (Present Subjunctive) be, как базовой формы глагола $\boldsymbol{b e}$, в придаточных предложениях уступки передает структуральное знание говорящего, а не непосредственный опыт наблюдателя. Отражение данным сочетанием понятийного знания подтверждается, во-первых, возможностью опущения в официальном стиле, то есть в ситуации, максимально абстрагированной от первоначального источника восприятия, глагола, следующего за этим предлогом (Swan, 2005, c. 559). Во-вторых, возможностью опущения глагола $\boldsymbol{b}$, что принципиально невозможно при употреблении форм сослагательного наклонения настоящего времени (Present Subjunctive), выражающих опыт наблюдателя. 


\section{Заключение}

Таким образом, мы пришли к следующим выводам. Первое - когнитивный механизм дистанцирования, лежащий в основе употребления формы сослагательного наклонения настоящего времени (Present Subjunctive), определяется противопоставлением непосредственного чувственного опыта наблюдателя и понятийного знания говорящего. Второе - сочетание модальных глаголов (Modal Verbs) may/might, can/could и should с простым инфинитивом (Simple Infinitive) передает только структуральное знание говорящего. Третье - простой инфинитив (Simple Infinitive) глагола be отражает не только структуральное знание говорящего, но и непосредственный опыт наблюдателя, с преобладанием последнего. Четвертое - сочетание предлога whatever и ему подобных и формы сослагательного наклонения настоящего времени (Present Subjunctive) глагола be в придаточных предложениях уступки описывает только структуральное знание говорящего.

Перспективы дальнейшего исследования состоят в изучении способов передачи феноменологического и понятийного знания в языке. Предполагается рассмотрение не только форм сослагательного наклонения прошедшего времени (Past Subjunctive), форм условного наклонения (Conditional Mood) и форм повелительного наклонения (Imperative Mood), но и именных форм представления различных типов знания в английском языке.

\section{Источники | References}

1. Емельянова О. В., Зеленщиков А. В., Петрова Е. С. A New University English Grammar (Грамматика современного английского языка): учебник для студ. высш. учеб. заведений / под ред. А. В. Зеленщикова, Е. С. Петровой. М. - СПб., 2003.

2. Есперсен О. Философия грамматики. М.: Иностранная литература, 1958.

3. Жулина Е. Б. Предложение с причастной конструкцией настоящего времени. Биокогнитивное осмысление // Филологические науки. Вопросы теории и практики. 2018. № 5-1.

4. Леонтьев А. Н. Деятельность. Сознание. Личность. М.: Политиздат, 1977.

5. Мамардашвили М. К. Стрела познания: набросок естественноисторической гносеологии. М.: Аванта+, 1996.

6. Моррис Ч. У. Основания теории знаков // Семиотика / под ред. Ю. С. Степанова. М.: Радуга, 1983.

7. Смирницкий А. И. Морфология английского языка. М., 1959.

8. Blomqvist J. Hyperreality: Beyond the Horizon Where Physics Meets Consciousness. Helsinki: Mindstream Publishing, 2021.

9. British National Corpus. 2022. URL: https://www.english-corpora.org/bnc/

10. Chomsky N., Berwick R. C. Why Only Us? Language and Evolution. Cambridge: The MIT Press, 2017.

11. Feldman Barrett L. Seven and a Half Lessons about the Brain. Boston: Mariner Books, 2020.

12. Hewson J. The Cognitive System of the French Verb // Current Issues in Linguistic Theory. Series IV. 1997. Vol. 147.

13. Kravchenko A. V. Two Views on Language Ecology and Ecolinguistics // Language Sciences. 2016. Vol. 2. Iss. 54.

14. Leech G. N. Meaning and the English Verb. L.: Longman, 1987.

15. Lewis M. The English Verb. An Exploration of Structure and Meaning. L.: Cambridge University Press, 1991.

16. Pinker S. Rationality: What It Is, Why It Seems Scarce, Why It Matters. N. Y.: Viking, 2021.

17. Swan M. Practical English Usage. L.: Oxford University Press, 2005.

18. Sweet H. A New English Grammar. Logical and Historical: in 2 parts. Oxford: Oxford University Press, 1958. P. II. Syntax.

19. Thomson A. J., Martinet A. V. A Practical English Grammar. Oxford: Oxford University Press, 1997.

20. Varela F. J., Thompson E., Rosch E. The Embodied Mind, Revised Edition: Cognitive Science and Human Experience. Cambridge: The MIT Press, 2017.

21. Verny T. R. The Embodied Mind: Understanding the Mysteries of Cellular Memory, Consciousness and Our Bodies. Cambridge: Pegasus Books, 2021.

\section{Информация об авторах | Author information}

RU Жулина Екатерина Борисовна ${ }^{1}$, к. филол. н.

${ }^{1}$ Санкт-Петербургский государственный университет

EN Zhulina Ekaterina Borisovna ${ }^{1}, \mathrm{PhD}$

${ }^{1}$ Saint-Petersburg State University

${ }^{1}$ minna80@mail.ru,e.zhulina@spbu.ru

\section{Информация о статье | About this article}

Дата поступления рукописи (received): 07.01.2022; опубликовано (published): 28.02.2022.

Ключевые слова (keywords): биология языка; адаптация; восприятие; наблюдатель; сослагательное наклонение настоящего времени; biology of language; adaptation; perception; viewer; Present Subjunctive. 